\title{
Underutilization of Qualitative Evidence in the Production and Implementation of Health Policy in Developing Countries
}

\author{
Yonas Getaye Tefera
}

\section{Yonas Getaye Tefera}

College of Medicine and Health Sciences, University of Gondar, Gondar, ETHIOPIA.

\section{Correspondence}

Yonas Getaye Tefera,

College of Medicine and Health

Sciences, University of Gondar,

Gondar, ETHIOPIA.

Email: yonas1get@gmail.com

History

- Submission Date: 19-07-2021

- Revised Date: 05-08-2021

- Accepted Date: 02-09-2021

DOI : 10.5530/ijmedph.2021.4.34

Article Available online

http://www.ijmedph.org/v11/i4

\section{Copyright}

(C) 2021 Phcog.Net. This is an openaccess article distributed under the terms of the Creative Commons Attribution 4.0 International license.

\section{BACKGROUND}

Historically, qualitative research was rarely utilized to investigate public health problems as compared to the widely employed quantitative methods. ${ }^{1}$ Public health is not only about quantitative numbers but also described qualitatively from the perspective of community beliefs and experiences. ${ }^{2}$ Qualitative methods will help for thorough understanding of health system challenges and inform public health programs by examining how is the strategy working, which is going well, what are the challenges. Therefore, a depth understanding of such complexities and overarching contributors beyond numerical measures are required. Addressing such elements were not possible by a simple quantitative approach alone and qualitative exploration of the sociocultural interactions, community views, prior experiences and beliefs behind the determinants of health are essential. ${ }^{3}$

Qualitative research in the development and implementation of health policy and guidance

Qualitative findings can be informative to production and implementation of policy as quantitative evidence does, but qualitative research in public health was little utilized. ${ }^{4}$ Expert opinions often used in place of qualitative evidences during policy production and implementation. As such, the assumed speculations of societal health and anecdotal experiences of experts may lead to flawed recommendations and ineffective implementations of health policies. But evidences from well conducted qualitative studies will provide insights from the perspectives of community values and expectations. Therefore, it will enhance the effectiveness and impact of public health programs.

Even though progresses are made in using qualitative researches for decision making, generally it is underutilized in the production of public health policy and guidance especially in low and middle-income countries. Production of policy and guidance are continually required to be based on the recommendations of best available evidence. However, public health recommendations are largely based on the systematic reviews of quantitative studies which may not reflect the feasibility and acceptability of public health programs. Moreover, evidence from the higher hierarchy of evidence of quantitative studies may not be available to implement new public health interventions in specific population groups or settings. Thus, public health policy development and implementation shall consider existing perceptions, beliefs and experiences of the community where the public health program intended to be delivered. This can be informed from the findings of either individualized qualitative studies or meta-synthesis (systematic reviews) of qualitative studies. ${ }^{5,6}$ Furthermore, qualitative methods are used together with standard quantitative measures to evaluate public health policy. It may also extend up to content analysis of the policy documents to assess the content, relevance, objectives and implementation strategies. The barriers for under-utilization of qualitative research findings in health policy decision making and its mitigation strategies are summarized in Table 1.

During emergencies and unprecedented outbreaks like COVID-19 pandemic, rapid qualitative studies can help to have quick snapshot of the multidimensional public health problems and contribute to better understanding of disease outbreaks and inform emergency response ${ }^{7}$ For instance, a qualitative study by Yoo et al. have helped to understand the global COVID-19 response similarities and differences across six countries (US, UK, China, Brazil, South Korea and Haiti) by assessing the COVID-19 guidelines in these countries. ${ }^{8}$ This may enable to recognize how countries are responding to the current global crisis, lessons to share and will help to inform decisions of global health institutions including WHO and other UN organs to spur global efforts. Therefore, it will guide the decision making of public health authorities to allocate resources and set public health measures during emergency.

\section{CONCLUSION}

The use of qualitative study in the production of public health policy and guidance is getting momentum. Despite the growing recommendation and importance of qualitative evidences, qualitative studies are still under-utilized in the development and implementation of public health policy in developing countries. Methodological limitations and various barriers were identified for underutilization of qualitative research in health policy and guidance. Therefore, new mitigation approaches and grading of recom-
Cite this article : Tefera YG. Underutilization of Qualitative Evidence in the Production and Implementation of Health Policy in Developing Countries. Int J Med Public Health. 2021;11(4):183-4. 


\begin{tabular}{|c|c|}
\hline Barriers & $\begin{array}{l}\text { Recommendations and mitigation } \\
\text { strategies }\end{array}$ \\
\hline $\begin{array}{l}\text { Policy expert's over-dependence } \\
\text { on the hierarchy of evidence } \\
\text { (which does not include qualitative } \\
\text { evidence) to produce health policy } \\
\text { and guidance }\end{array}$ & $\begin{array}{l}\text { Moving from the hierarchy to } \\
\text { appropriateness of evidence. }{ }^{9} \text { There } \\
\text { were also attempts to assess rigor } \\
\text { and provide hierarchy of evidence in } \\
\text { qualitative studies. } .^{10}\end{array}$ \\
\hline $\begin{array}{l}\text { Qualitative research has } \\
\text { traditionally been excluded from } \\
\text { systematic reviews which guidance } \\
\text { and policies are regularly based on. }\end{array}$ & $\begin{array}{l}\text { Systematic reviews and evidence } \\
\text { synthesis from qualitative findings are } \\
\text { increasing }\end{array}$ \\
\hline $\begin{array}{l}\text { Limited generalizability of } \\
\text { findings to other settings (seen } \\
\text { as subjective while quantitative } \\
\text { finding considered as objective and } \\
\text { trustworthy). }\end{array}$ & $\begin{array}{l}\text { Evidence meta-synthesis and de- } \\
\text { contextualization of the primary } \\
\text { qualitative studies by third order } \\
\text { interpretations of systematic reviews. }{ }^{6,11}\end{array}$ \\
\hline $\begin{array}{l}\text { Limited guidance on how to assess } \\
\text { and use qualitative evidence in } \\
\text { health policy and practice. }\end{array}$ & $\begin{array}{l}\text { WHO have recommended a new } \\
\text { approach called GRADE-CERQual } \\
\text { (Grading of Recommendations } \\
\text { Assessment, Development and }\end{array}$ \\
\hline $\begin{array}{l}\text { Quantitative bias minimization } \\
\text { criteria often applied incorrectly to } \\
\text { qualitative studies to have grading } \\
\text { recommendations of evidence for } \\
\text { policy productions }\end{array}$ & $\begin{array}{l}\text { Evaluation-Confidence in the evidence } \\
\text { from reviews of qualitative research). }{ }^{12}\end{array}$ \\
\hline $\begin{array}{l}\text { Limited number of researchers } \\
\text { engaged in qualitative researches } \\
\text { and meta-synthesis of evidences, } \\
\text { particularly in LMICs. }{ }^{13}\end{array}$ & $\begin{array}{l}\text { Promote findings from qualitative } \\
\text { studies, establishing institutions } \\
\text { responsible for evidence- synthesis } \\
\text { and research translations into tailored } \\
\text { public health policy. }\end{array}$ \\
\hline $\begin{array}{c}\text { Implementation and structural } \\
\text { problems to uptake and utilize } \\
\text { qualitative findings. } .^{13}\end{array}$ & \\
\hline
\end{tabular}

mendation for qualitative findings are emerging to increase the use of qualitive evidence in the production and implementation of public health policy.

\section{CONFLICT OF INTEREST}

The author declares no conflict of interest.

\section{REFERENCES}

1. Faltermaier T. Why public health research needs qualitative approaches. Subjects and methods in change. Eur J Public Health. 1997;7(4):357-63. doi: 10.1093/eurpub/7.4.357.

2. Isaacs AN. An overview of qualitative research methodology for public health researchers. Int J Med Public Health. 2014;4(4):318-23. doi: 10.4103/22308598.144055

3. Lewin S, Glenton C. Are we entering a new era for qualitative research? Using qualitative evidence to support guidance and guideline development by the World Health Organization. Int J Equity Health. 2018;17(1):126. doi: 10.1186/ s12939-018-0841-x, PMID 30244675.

4. Fisher MP Hamer MK. Qualitative methods in health policy and systems research: A framework for study planning. Qual Health Res. 2020:1049732320921143:30(12):1899-912. doi: 10.1177/1049732320921143 PMID 32449451.

5. Saini M, Shlonsky A. Systematic synthesis of qualitative research. USA: Oxford University Press; 2012.

6. Thomas J, Harden A. Methods for the thematic synthesis of qualitative research in systematic reviews. BMC Med Res Methodol. 2008;8(1):45 doi: 10.1186/1471-2288-8-45, PMID 18616818

7. Vindrola-Padros C, Chisnall G, Cooper S, Dowrick A, Djellouli N, Symmons SM, et al. Carrying out rapid qualitative research during a pandemic: emerging lessons from COVID-19. Qual Health Res. 2020;30(14):2192-204. doi: 10.1177/1049732320951526, PMID 32865149

8. Yoo JY, Dutra SVO, Fanfan D, Sniffen S, Wang H, Siddiqui J, et al. Comparative analysis of COVID-19 guidelines from six countries: A qualitative study in the US. China, South Korea, the UK: Brazil and Haiti; 2020

9. Parkhurst JO, Abeysinghe S. What constitutes "good" evidence for public health and social policy-making? From hierarchies to appropriateness. Soc Epistemol. 2016;30(5-6):665-79. doi: 10.1080/02691728.2016.1172365.

10. Daly J, Willis K, Small R, Green J, Welch N, Kealy M, Hughes E A hierarchy of evidence for assessing qualitative health research. J Clin Epidemiol. 2007;60(1):43-9. doi: 10.1016/j.jclinepi.2006.03.014.

11. Finfgeld-Connett $D$. Generalizability and transferability of meta-synthesis research findings. J Adv Nurs. 2010;66(2):246-54. doi: 10.1111/j.1365-2648.2009.05250.x PMID 20423407.

12. Langlois EV, Tunçalp Ö, Norris SL, Askew I, Ghaffar A. Qualitative evidence to improve guidelines and health decision-making. Bull World Health Organ 2018;96(2):79-79A. doi: 10.2471/BLT.17.206540, PMID 29403107.

13. Glenton C, Lewin S, Gülmezoglu AM. Expanding the evidence base for global recommendations on health systems: strengths and challenges of the OptimizeMNH guidance process. Implement Sci. 2016;11:98. doi: 10.1186/s13012016-0470-y, PMID 27430879. 